\title{
Application of Induction Heating for Brazing Parts of Solar Collectors
}

\author{
Kristína Demianová ${ }^{1}$, Milan Ožvold $^{1}$, Milan Turňa ${ }^{1}$ \\ ${ }^{1}$ Slovak University of Technology, Faculty of Materials Science and Technology, J. Bottu 25, 917 24 Trnava, Slovakia \\ Correspondence to: kristina.demianova@gmail.com
}

\begin{abstract}
This paper reports on the application of induction heating for brazing parts of solar collectors made of Al alloys. The tube-flange joint is a part of the collecting pipe of a solar collector. The main task was to design an induction coil for this type of joint, and to select the optimum brazing parameters. Brazing was performed with AlSi12 brazing alloy, and corrosive and non-corrosive flux types were also applied. The optimum brazing parameters were determined on the basis of testing the fabricated brazed joints by visual inspection, by leakage tests, and by macro- and micro-analysis of the joint boundary. The following conditions can be considered to be the best for brazing Al materials: power $2.69 \mathrm{~kW}$, brazing time $24 \mathrm{~s}$, flux BrazeTec F32/80.
\end{abstract}

Keywords: aluminium alloy, brazing, induction heating.

\section{Introduction}

Induction heating is widely used nowadays in many industrial applications, e.g. in material melting processes, heat treatment, hot forming, and also for welding and brazing metallic materials. Modern induction heating provides reliable, repeatable, non-contact and energy-efficient heat in a minimal amount of time, without a flame. Solid state systems are capable of heating very small areas within precise production tolerances, without disturbing the individual metallurgical characteristics. For larger volume applications and/or quality-dependent processes, parts can be brazed with induction under a controlled atmosphere without flux or any additional cleaning steps $[2,3]$. The advantages of induction heating over conventional heating processes in furnaces or applying other heat sources are power efficiency and friendliness to the living environment.

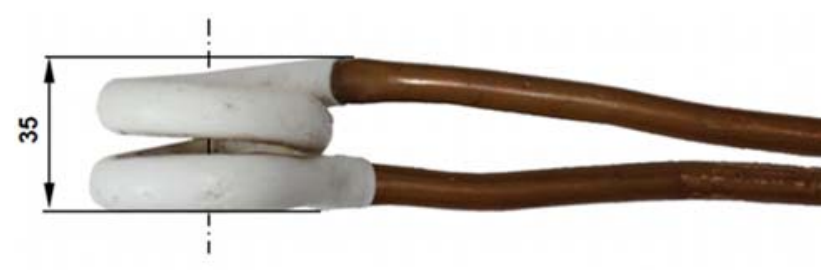

a)

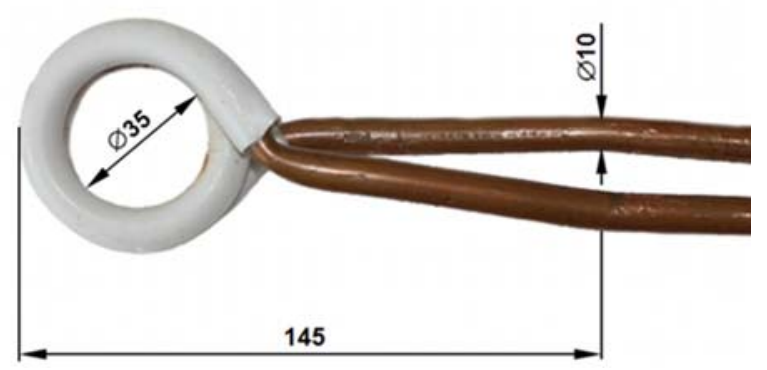

b)

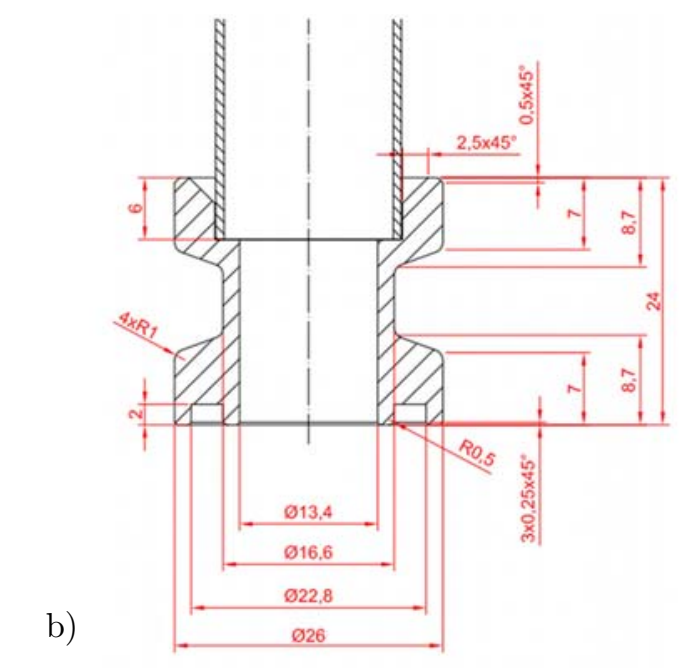

The main aims of this paper are to report on the design of an induction coil for induction brazing of parts of solar collectors, to determine the optimum brazing parameters, and to select suitable basic materials, and a suitable brazing alloy and flux. This work is linked with our previous study [1].

\section{Experimental}

The brazing experiments were performed using HRF 15 equipment, produced for high-frequency induction heating. For this technology, the design of a suitable induction coil is very important. Experience acquired from previous research formed the basis for the design of the induction coil and also the heating of the brazed parts (metallic materials). The coil and its basic dimensions are shown in Figure 1.

Figure 1: Dimensions of components a) inductor, b) brazed tubes 
Table 1: Chemical composition of AW 6082 alloy [wt. \%]

\begin{tabular}{|c|c|c|c|c|c|c|c|c|}
\hline $\mathbf{S i}$ & $\mathbf{F e}$ & $\mathbf{C u}$ & $\mathbf{M n}$ & $\mathbf{M g}$ & $\mathbf{C r}$ & $\mathbf{Z n}$ & $\mathbf{T i}$ & $\mathbf{A l}$ \\
\hline $0.7-1.3$ & 0.5 & 0.1 & $0.4-1.0$ & $0.6-1.2$ & 0.25 & 0.2 & 0.1 & balance \\
\hline
\end{tabular}

Table 2: Chemical composition of AW 3000 alloy [wt. \%]

\begin{tabular}{|c|c|c|c|c|c|c|c|}
\hline $\mathbf{S i}$ & $\mathbf{F e}$ & $\mathbf{C u}$ & $\mathbf{M n}$ & $\mathbf{M g}$ & $\mathbf{Z n}$ & $\mathbf{C r}$ & $\mathbf{A l}$ \\
\hline $0.05-0.15$ & $0.06-0.35$ & max. 0.1 & $0.3-0.6$ & $0.02-0.20$ & $0.05-0.3$ & max. 0.25 & balance \\
\hline
\end{tabular}

Table 3: Chemical composition of brazing alloy type Al 104 [wt. \%]

\begin{tabular}{|c|c|c|c|c|c|c|c|}
\hline $\mathbf{S i}$ & $\mathbf{F e}$ & $\mathbf{C u}$ & $\mathbf{M n}$ & $\mathbf{M g}$ & $\mathbf{Z n}$ & $\mathbf{T i}$ & $\mathbf{A l}$ \\
\hline $11-13$ & 0.6 & max. 0.3 & 0.15 & 0.1 & 0.2 & max. 0.15 & balance \\
\hline
\end{tabular}

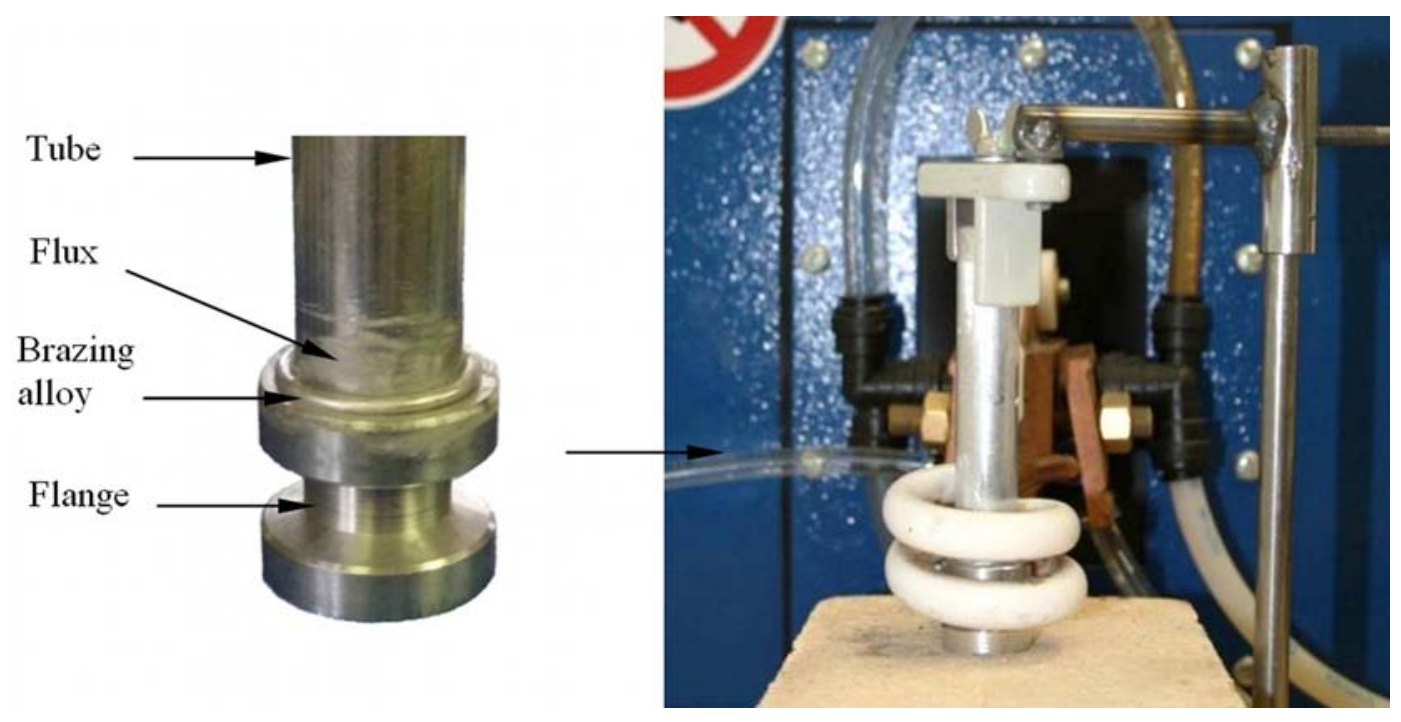

Figure 2: Situation of joined parts in the inductor

$\mathrm{Cu}$ and its alloys are the most widely-used material for fabricating the collecting pipe of solar collectors. However, $\mathrm{Al}$ is nowadays becoming an important substitute material for this application, owing to its unique utility properties. It has good corrosion resistance, it is also lighter and cheaper than copper, and it is $100 \%$ recyclable. The selection of materials for the parts of the collecting pipe therefore focused on the selection of suitable Al alloys. The flange was fabricated of from Al alloy type AW 6082, and the tube was fabricated from alloy type 3000 . The chemical composition of these materials is presented in Tables 1 and 2. Brazing alloy type Al 104 (Table 3) in the form of wire was used for fabricating the flange-tube joint. A tubular solder type AlSi12 filled with Nocolok flux was also used. During the brazing process were used following fluxes: BrazeTec F30/70 (FL 10), BrazeTec F32/80 (FL 20) and Nocolok.

Prior to brazing proper, the soldered areas were cleaned from surface impurities and oxides, and were subsequently degreased. Then an appropriate amount of flux was deposited on the brazed surfaces (in the case of brazing alloy, in the form of a wire) and these were situated to the centre of the axis of the induction coil, see Figure 2.

The process parameters during brazing were set on the basis of a visual inspection at a stable frequency of $360 \mathrm{kHz}$. External defects of the joints were observed, e.g.: insufficient filling, porosity damage to the surface, local melting, and rough joint surfaces. Another important consideration was the precise positioning of the joined parts in the inductor, and correct selection of the intensity (power) related to the brazing duration.

Figure 3a shows the P1 joint, which was fabricated with the application of FL 10 flux and AlSi12 brazing alloy at output power $2.26 \mathrm{~kW}$. The brazing time was $35 \mathrm{~s}$. Melting of the flange, and incomplete filling of the clearance with the brazing alloy was observed. In the case of joint P2 (Figure 3b), higher power $(2.9 \mathrm{~kW})$ was selected, which led to lo- 


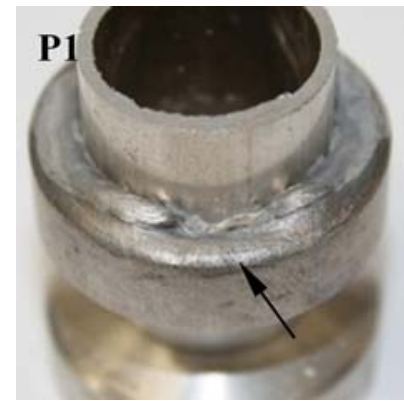

a) $2.26 \mathrm{~kW}, 35 \mathrm{~s}, \mathrm{FL} 10$

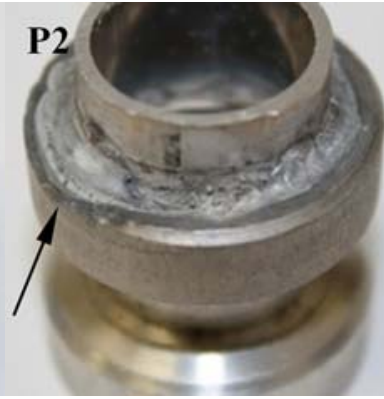

b) $2.9 \mathrm{~kW}, 18 \mathrm{~s}, \mathrm{FL} 10$

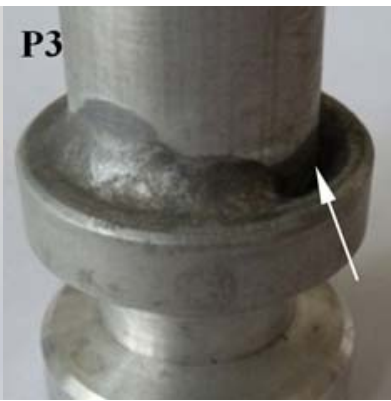

c) $2.6 \mathrm{~kW}, 25 \mathrm{~s}, \mathrm{FL} 10$

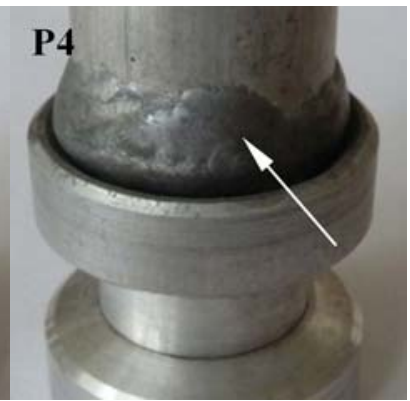

d) $2.6 \mathrm{~kW}, 25 \mathrm{~s}$, FL10

Figure 3: Brazed joints fabricated with various parameters

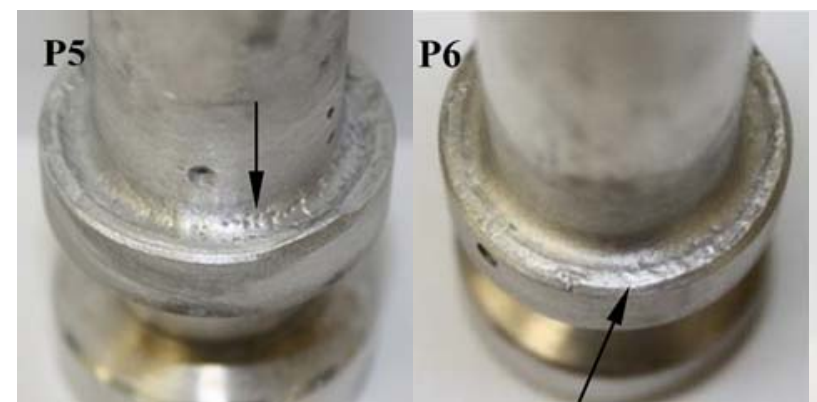

a) $2.6 \mathrm{~kW}, 26 \mathrm{~s}$, Nocolok b) $2.6 \mathrm{~kW}, 28 \mathrm{~s}, \mathrm{FL} 20$

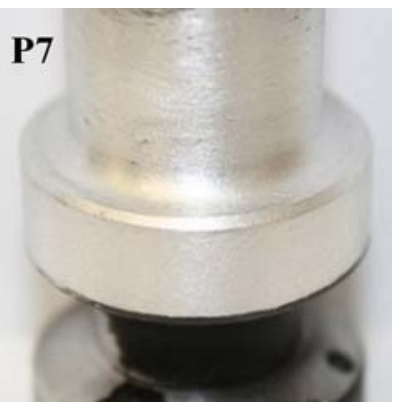

c) $2.69 \mathrm{~kW}, 24 \mathrm{~s}, \mathrm{FL} 20$

Figure 4: Brazed joints fabricated with various parameters
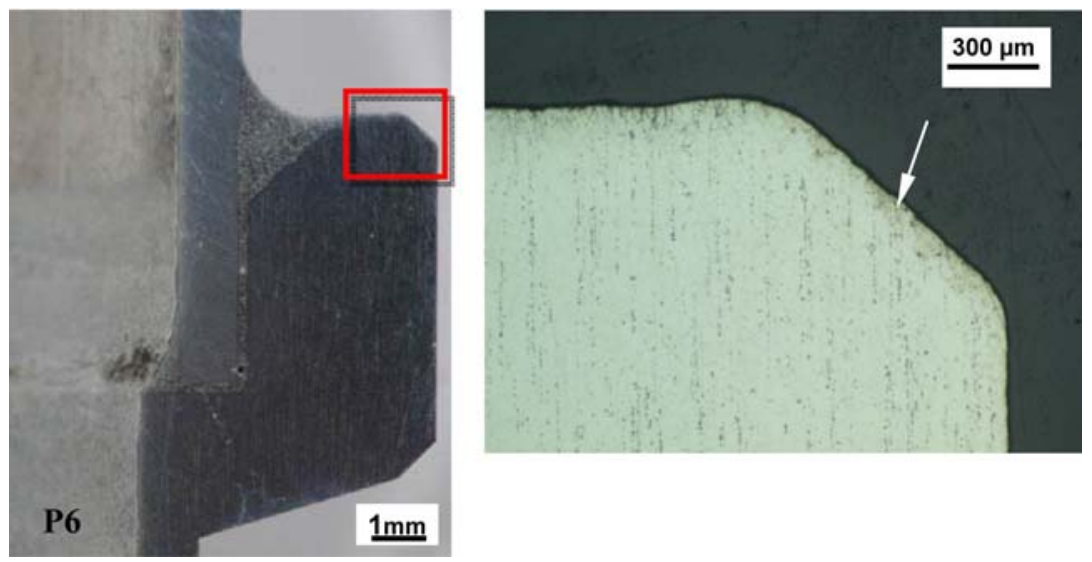

$2.6 \mathrm{~kW}, 26 \mathrm{~s}, \mathrm{FL} 20$

Figure 5: Macrostructure of the brazed joint of specimen P6 with a detail of the microstructure

cal melting of the flange at brazing time $18 \mathrm{~s}$. In the case of joints P3 and P4 (Figures 3c,d), which were fabricated at $2.6 \mathrm{~kW}$ power and brazing time $25 \mathrm{~s}$, insufficient filling with the brazing alloy was also observed when FL 10 flux was applied, and then removed from the joint. The brazing alloy wetted just the parent metal of the tube.

Experience obtained when fabricating previous joints has shown that it is suitable to use power around $2.6 \mathrm{~kW}$ to prevent the flange melting down. Nocolok type flux (Figure 4a) was applied for fabricating joint $\mathrm{P} 5$. The brazing time was $26 \mathrm{~s}$. After removing the residual flux, we observed poros- ity damaging the surface and local melting down of the parent material. FL 20 flux was used for brazing joint P6. The brazing time was $28 \mathrm{~s}$ at output power $2.6 \mathrm{~kW}$. After the residual flux is removed from the joint, local melting down of the parent metal is visible (Figure 4b). With a slight power increase to $2.69 \mathrm{~kW}$, joint P7 was fabricated at time $24 \mathrm{~s}$. When the flux residues were removed, it was obvious (Figure 4c) that at this power setting and flux selection, there was neither melting of the flange, nor any formation of porosity damaging the surface. The joint macrostructure was observed on specimen P6 (Figure 5). The brazing alloy sufficiently filled 

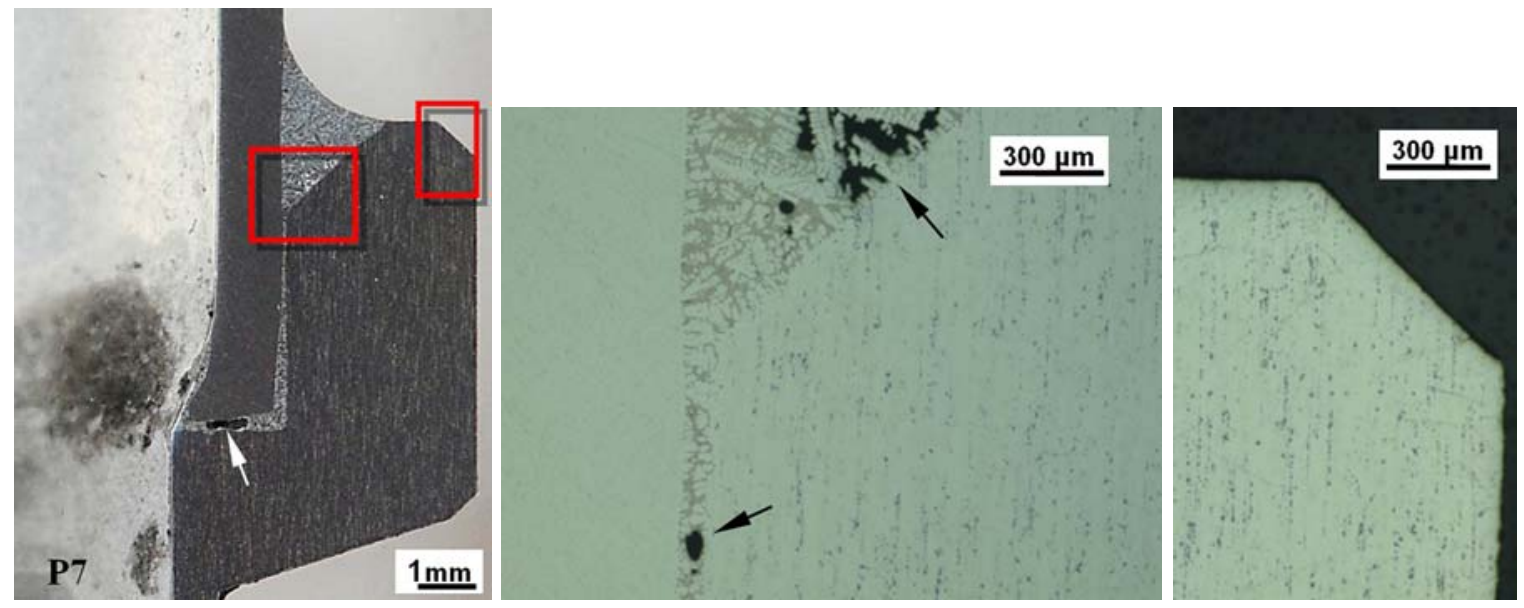

$2.69 \mathrm{~kW}, 24 \mathrm{~s}$, FL20

Figure 6: Macrostructure of a brazed joint of specimen P7, with a detail of the microstructure

the required joint clearance. Isolated pores were observed in the capillary gap. The detailed view of the microstructure shows the grain growth in the flange edge zone.

Figure 6 shows the macrostructure of joint P7. When the microstructure in the flange edge zone of was inspected, no grain growth was observed. This was due to the power increase during brazing and thus also due to suitable shortening of the the brazing time. Isolated voids (shrinkage holes) occurred in the brazing alloy microstructure.

The quality of the joints was evaluated by light microscopy and also by a leakage test. The leakage test was performed at Thermosolar Company, using the Thermosolar leakage test equipment at a pressure of $1 \mathrm{MPa}$. All joints that were tested passed the test.

\section{Discussion}

The following conclusions may be drawn from the results. Precise positioning of the brazed parts against the inductor was very important when fabricating the joints, in order to prevent local melting of the flange edges. Melting of the flange edges was also affected by low power and subsequently by a longer brazing time. It can be stated that the brazing time to a certain measure also depends on the efficiency of each flux type and its working temperature. It was found that the BrazeTec F30/70 (FL 10) flux type was not suitable for brazing the AlSi1MgMn alloy that the flange was made of. When this flux was applied, the brazing alloy wetted only the surface of the AlMn1 tube. The Nocolok flux type caused porosity on the brazing alloy surface. The BrazeTec F32/80 (FL 20) flux type can be considered as best for joint $\mathrm{P}$. This joint was fabricated with the flux at $2.69 \mathrm{~kW}$ power for a duration of $24 \mathrm{~s}$.

\section{Conclusions}

Ever increasing demands for solar collectors, together with growth in competition, require ongoing technological progress and innovative elements in order to maintain competitive advantages, product attractiveness and last but not least cost savings. Innovative technology for joining the parts of the collecting pipe of collectors is therefore desirable.

The aim of our work was to develop a progressive technology for joining the parts of solar collectors as a replacement for obsolete flame brazing technology. It was of equal importance to find a suitable alternative for the copper that the collecting pipe of the solar collectors was made of. On the basis of a literature study, brazing with high-frequency induction heating of aluminium alloys with a eutectic AlSi12 brazing alloy type was selected. When brazing aluminium alloys, it is of great importance to select a suitable flux. A series of brazed joints were fabricated with three types of fluxes (Nocolok, BrazeTec F32/80 and BrazeTec F30/70) and the AlSi12brazing alloy type. The quality of the fabricated joints was assessed by an visual inspection, a leakage test, and optical microscopy. On the basis of our results, it can be concluded that the brazing technology with induction heating that has been developed is suitable for joining $\mathrm{Al}$ alloys. In future work, we will carry out corrosion, thermodynamic and fatigue tests on the joints.

\section{Acknowledgement}

This work was carried out with support from GA VEGA MŠ VVŠ SR and SAV. projects No. 1/2594/12 and No. 1/1000/09. 


\section{References}

[1] Demianová, K., Behúlová, M., Ožvold, M., Turňa, M., Sahul, M.: Brazing of aluminium tubes using induction heating, Advanced Materials Research, Vol. 463-464, 2012, p. 1405-1409.
[2] Rapoport, E., Pleshivtseva, Y.: Optimal Control of Induction Heating Processes. Taylor \& Francis Group, LLC, USA, 2007. ISBN-10 0-8493-3754-2.

[3] Rudnev, V., et al.: Handbook of Induction Heating. New York : Marcel Dekker, 2003. ISBN 0-8247-0848-2. 